\title{
Advanced Deterioration Diagnosis Model for Building External Wall Tiles
}

\author{
Sy-Jye Guo \\ Department of Civil Engineering, National Taiwan University, Taiwan, China \\ Email:sjguo@ntu.edu.tw
}

How to cite this paper: Guo, S.-J. (2018) Advanced Deterioration Diagnosis Model for Building External Wall Tiles. World Journal of Engineering and Technology, 6, $1-12$. https://doi.org/10.4236/wjet.2018.62B001

Received: March 20, 2018

Accepted: May 19, 2018

Published: May 22, 2018

\begin{abstract}
In 1981 Taiwan entered a period of intense construction, meaning that today many buildings are more than 30 years old. Lack of maintenance has led to frequent safety incidents involving external walls. This study focuses on a deterioration diagnostic model for external wall tiles of aged buildings, using both stage land stage 2 diagnostic methods. The visual test results are categorized based on impact on public safety, and renovation strategies are proposed. Stage 1 diagnosis mainly adopted the DER visual inspection deterioration assessment method. For enhance the accuracy, this research adopted the Infrared Thermal Imaging detection method to double confirm the visual inspection results. After producing an external wall tile Condition Indicator (CI). For stage 1 diagnostic results that fall in a gray area, stage 2 diagnosis was carried out using a tap tone test, followed by fast Fourier transform and pattern recognition to analyze the tapping results. Finally, the study provides a deterioration evaluation criteria for external wall tiles replacement recommendations and a standard operating procedure for deterioration diagnosis. The study also recommends directions for future amendment of regulations, and provides a basis of reference for the government in determining urban renewal, renovation and maintenance strategies.
\end{abstract}

\section{Keywords}

DER Model, Tap Tone Method, Infrared Thermal Imaging Method, Building External Wall Tiles

\section{Introduction}

In recent years, there have been frequent safety incidents involving external walls of buildings. The most common incidents include falling tiles, falling advertising signage and falling of exposed pipelines, causing serious impact to the 
surrounding environment and public safety. On October 14, 2013, a tile falling incident in Keelung City, Taiwan, resulted in a fatality. According to research data, construction in Taiwan peaked in the years 1981 and 1994. If we take 30 years as the watershed for significant deterioration in Taiwan buildings, we can posit that the peak for safety check requirements for Taiwanese buildings should thus be 2011 and 2024 [1]. Integrating news relating to fatalities in tile falling incidents in Taiwan, it can be seen that there is an immediate need for a complete diagnostic mechanism and preventive method to prevent the further occurrence of such public safety incidents.

To effectively drive external wall replacement safety checks and studies on evaluation systems, relevant empirical results and evaluation criteria should be available as a reference for the industry. Our study aims to provide a basis of reference and an evaluation method for use in external wall tile diagnosis through data collection and empirical research.

\section{Evaluation Method for Visual Diagnosis of External Wall Tiles}

\subsection{Visual Diagnostic Evaluation Method}

This study adopts the D.E.R. \& U. evaluation method used in the "Taiwan Bridge Management System" [2], and the visual diagnostic evaluation chart for external wall tiles adopted by Chiang [3] and Guo [4]. However, it is our observation that these are insufficient for Taiwan's construction environment. Hence, our study proposes modification of the visual diagnostic evaluation chart for external wall tiles as shown in Table 1 (with addition of remarks) in order to better address the local construction environment.

With regards to visual diagnosis the study aims to determine if there is an

Table 1. Building façade tile visual diagnosis evaluation criteria table.

\begin{tabular}{|c|c|c|c|c|c|}
\hline & 0 & 1 & 2 & 3 & 4 \\
\hline $\mathrm{D}$ & Normal & $\begin{array}{c}\text { Expand, } \\
\text { Discoloration, } \\
\text { Efflorescence }\end{array}$ & $\begin{array}{c}\text { Tiles falling, } \\
\text { paint layer } \\
\text { visible }\end{array}$ & $\begin{array}{c}\text { Stucco layer peeled, } \\
\text { protection layer } \\
\text { visible }\end{array}$ & $\begin{array}{c}\text { Protection } \\
\text { layer damaged }\end{array}$ \\
\hline $\mathrm{E}$ & $0 \%$ & $1 \%-5 \%$ & $6 \%-10 \%$ & $1 \%-15 \%$ & $16 \%$ or more \\
\hline \multirow{3}{*}{$\mathrm{R}$} & No effect & $\begin{array}{c}\text { A few specific } \\
\text { users }\end{array}$ & $\begin{array}{c}\text { Many specific } \\
\text { users }\end{array}$ & $\begin{array}{c}\text { A few unspecified } \\
\text { users }\end{array}$ & $\begin{array}{c}\text { Many } \\
\text { unspecified } \\
\text { users }\end{array}$ \\
\hline & $\begin{array}{c}\text { Road } \\
\text { width }<1 \mathrm{M}\end{array}$ & $\begin{array}{c}1-2 \mathrm{M} \text { road } \\
\text { width }\end{array}$ & $\begin{array}{c}2-6 \mathrm{M} \text { road } \\
\text { width }\end{array}$ & $\begin{array}{c}6-12 \mathrm{M} \\
\text { road width }\end{array}$ & $\begin{array}{c}\text { Road } \\
\text { width }>12 \mathrm{M}\end{array}$ \\
\hline & 0 to 1 floor & 1 to 3 floor & 4 to 6 floor & 7 to 9 floor & $\begin{array}{c}10 \text { floors or } \\
\text { more }\end{array}$ \\
\hline
\end{tabular}

Note 1: Inspector should pay attention to building external corner (like exposed structure), opening, parapet, balcony, location of attachment to wall (like signage or rain awning), which are the places that tiles are prone to damage. Note 2: Inspector should determine $\mathrm{R}$ value, and carefully observe the circulation is near arcade or the building has setback, or consider lower $\mathrm{R}$ value under the condition not to affect public safety. Data source: Chiang, Li-Wei et al., 2013. 
immediate threat to public safety based on a relationship between tile peeling and structure of the external wall structure. In general, external wall structure can be split into a structural protective layer, stucco layer, adhesive layer and tile layer. The study posits that when tiles begin to discolor, peeling may occur. Hence, this is defined as Level 1 deterioration. Following the structural order, the other three levels can be categorized as: tiles falling, paint layer visible (bulging can be considered as a peeling off from the stucco layer); and the stucco layer peeled, protection layer visible; and the structural protection layer is damaged. Based on differing degree of damage to an external wall's structure, the deterioration condition is determined (as shown in Table 2).

In terms of extent of deterioration, the study applies the ratio (as a percentage) of deterioration area to the total surface area of the external wall as a basis for determining deterioration extent. Based on the data collected from cases analyzed, the study estimated the likelihood of repeat deterioration. After studying cases and using CAD software to perform statistical analysis, it was observed that the extent of deterioration mainly fell between $4 \%$ and $18 \%$. For purposes of systematic diagnosis and identification, the study defines a deterioration range of between $0 \%$ to $15 \%$, split into five segments (Table 3 ).

In terms of impact on public safety, the study uses the degree of impact on passers-by, building height, and width of adjacent roads as a basis for evaluation. The building is deemed to have an impact on public safety if any one of these three criteria is satisfied. During evaluation, evaluators observe such considerations as whether pedestrian routes approach the "five foot way", whether the width of the sidewalk facilitates walking, or whether building shrinkage has

Table 2. Deterioration degree.

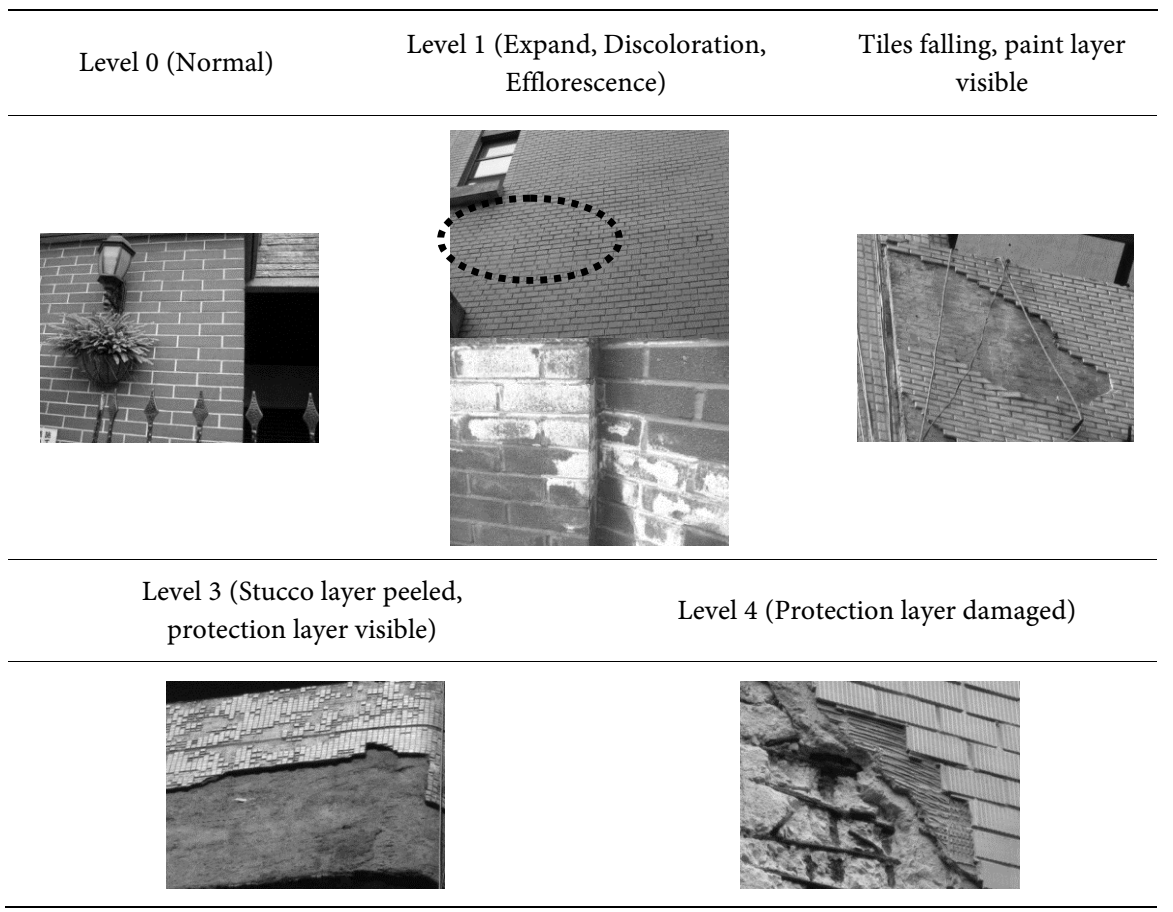


Table 3. Deterioration extent.

\begin{tabular}{ccc} 
Level $0(0 \%)$ & Level 1(1\%-5\%) & Level 2(6\%-10\%) \\
\hline Level $3(11 \%-15 \%)$ & Level $4(16 \%$ or more) \\
\hline & & \\
\hline
\end{tabular}

occurred (Table 4).

\subsection{Range of External Wall Tile Deterioration}

Through D.E.R. external wall tile visual diagnosis, the study computed condition indicators of the 46 case studies, and presented preliminary inspection results. Condition Index (CI) refers to the evaluated value of the external wall tile deterioration condition through visual diagnosis. These indicators allow us to understand the current condition of the external walls of a building. The higher the $\mathrm{CI}$ value, the better the overall condition of the external wall, and vice versa. Hence, the limit values and definition of the overall condition indicators need to be set including range and limit values for maintenance and repair considerations. If the building's external wall aggregate indicator is lower than this value or range, a second diagnosis, repair recommendation or renovation evaluation has to be performed. The indicator can also be used to analyze estimated useful life, and the CI value can be used for estimating the trend of external wall deterioration. Upon completion of this evaluation and related calculations, the evaluators may make repair or renovation recommendations on external wall tiles that display conditions of serious damage or deterioration.

The study adopts the external wall tile condition indicator equation proposed by Chiang [3], and Guo [4]. Based on the actual condition, the calculation method and parameter definitions are adjusted to cater for external wall tile evaluation in the future. The adjusted equation is as follows Equation (1):

$$
C I=100-100 \times \frac{(D+E) \times R}{(4+4) \times 4}
$$

Equation (1) derives the relative degree of the external wall tile inspected. The result ranges from 0 - 100, indicating the external wall tile health level. 0 indicates the lowest health level, while 100 indicates the highest. Hence, in the equation, the result of the diagnostic object is subtracted from the full score to derive the relative value. $(D+\mathrm{E}) \times \mathrm{R}$, the deterioration degree $(D)$ and deterioration 
Table 4. Relevancy with the public safety.

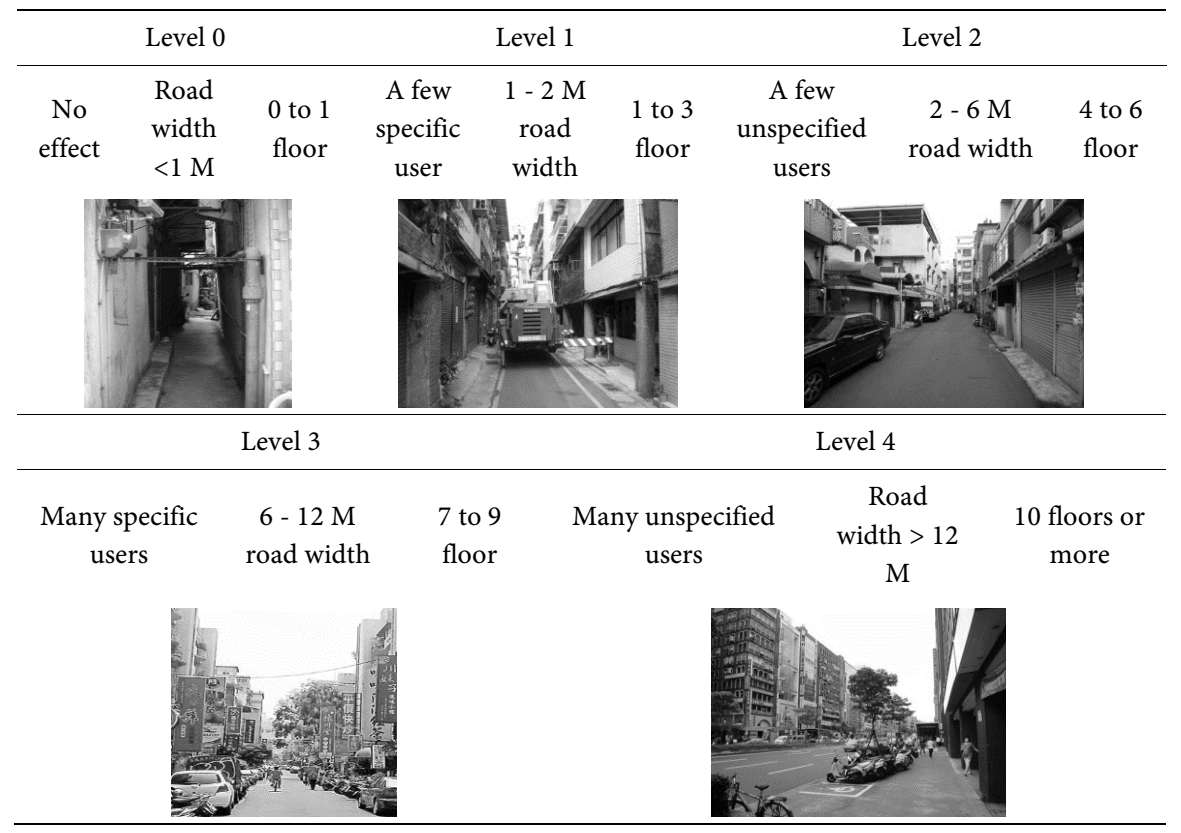

extent $(E)$ from visual inspection, which share impact attributes, are summed together, and then multiplied by $R$, the public safety impact value. In the Equation $(1)(4+4) \times 4,4$ is the optimal decision value in line with the visual diagnosis method.

The study includes all possible results of visual diagnosis into Equation (1), resulting in 125 possibilities $(\mathrm{D} 0 \sim 4 \times \mathrm{E} 0 \sim 4 \times \mathrm{R} 0 \sim 4=125)$. As the aim of the study is to facilitate prompt judgment on old buildings which already have external wall tile deterioration, this research exclude those with 0 deterioration degree, deterioration extent and impact on public safety, reducing the number of possible results to 64 . We take the mean of the condition indicator result, and move one standard deviation in both directions to derive four ranges to facilitate definition of the diagnostic results. After calculation, there were 125 possibilities, with a mean of 61.04 and standard deviation of 22.23. For easy categorization the study used integers for the ranges, in the order of: below 38,39 to 60,61 to 82 , and above 83 (Figure 1 and Table 5).

The focus of the study is public safety. Hence, the value of $\mathrm{R}$ indeed impacts the $\mathrm{CI}$ value results. After evaluating the 64 possibilities, if the CI value falls within Grade 1, it indicates the impact on public safety (R) is lowest, and D and $\mathrm{E}$ values are good. Therefore, it is sufficient to carry out annual inspections only. If the CI value falls within Grade 4, the impact on public safety is higher, and the $\mathrm{D}$ and $\mathrm{E}$ values are poor. The study recommends immediate facade renovation. If the CI value falls within Grade 2 and 3, and as the limitations of visual inspection mean that external wall tile cavity or detachment are not easily detected, there is thus a higher possibility of human error. The study recommends that, if $\mathrm{R}=1$, indicating a lower public safety impact, inspection on external wall tiles can be done at least once a year. If $\mathrm{R}=2$ or 3 , indicating a higher public safety 


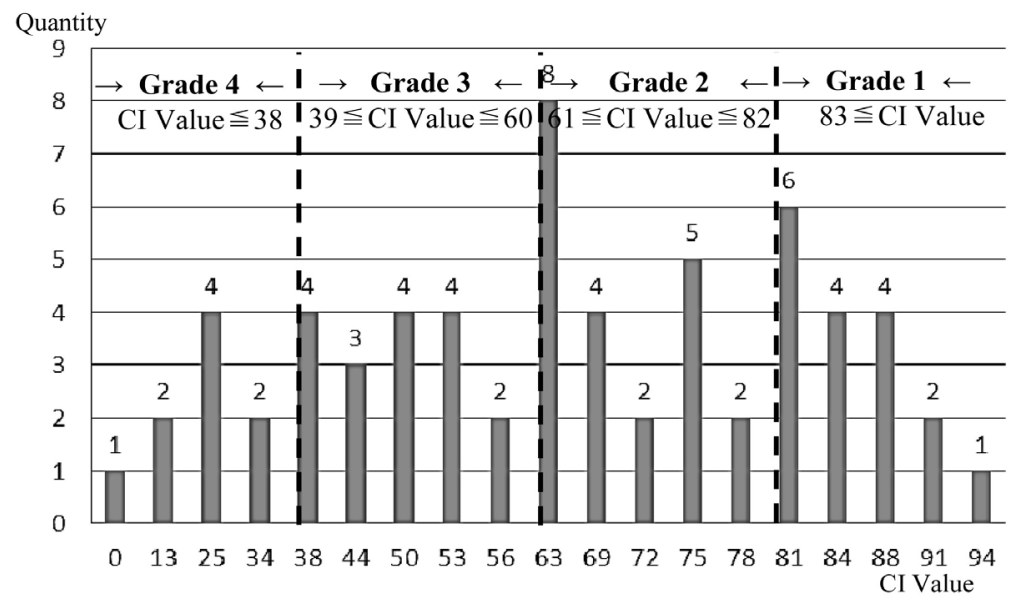

Figure 1. Grades for CI

Table 5. Visual diagnosis public safety classification table.

\begin{tabular}{|c|c|c|c|c|}
\hline $\begin{array}{l}\text { Diagnostic } \\
\text { Level }\end{array}$ & Method & $\begin{array}{c}\text { Condition } \\
\text { Index } \\
\text { classification }\end{array}$ & $\begin{array}{l}\text { Determine } \\
\text { the grade }\end{array}$ & Proposed renovation principle \\
\hline \multirow{4}{*}{ Stage 1} & \multirow{4}{*}{$\begin{array}{c}\text { D.E.R } \\
\text { Visual } \\
\text { Diagnostic } \\
\text { Method }\end{array}$} & $83 \leq \mathrm{CI}$ & 1 (Good) & $\begin{array}{l}\text { Healthy, no immediate harm, } \\
\text { regular check once a year }\end{array}$ \\
\hline & & $61 \leq \mathrm{CI} \leq 82$ & 2 (Not bad) & $\begin{array}{c}\mathrm{R}=1 \text {, check once a year. } \\
\mathrm{R}=2,3 \text {, partial external } \\
\text { wall tap tone diagnosis } \\
\text { (top and ground floor) } \\
\mathrm{R}=4 \text {, comprehensive external } \\
\text { wall tap tone diagnosis }\end{array}$ \\
\hline & & $38 \leq \mathrm{CI} \leq 60$ & $\begin{array}{c}3 \text { (Attention } \\
\text { needed) }\end{array}$ & $\begin{array}{c}\mathrm{R}=2,3 \text {, partial external } \\
\text { wall tap tone diagnosis } \\
\text { (top and ground floor) } \\
\mathrm{R}=4 \text {, comprehensive external } \\
\text { wall tap tone diagnosis }\end{array}$ \\
\hline & & $\mathrm{CI}<38$ & $4(\mathrm{Bad})$ & $\begin{array}{l}\text { External wall renovation are } \\
\text { recommended }\end{array}$ \\
\hline
\end{tabular}

impact, it is recommended to carry out tap tone diagnosis on part of the facade (top and ground floor) to determine if cavity or detachment conditions are present. If $\mathrm{R}=4$, indicating the highest impact on public safety, it is recommended to carry out overall tap tone diagnosis of the external tiles of building.

\subsection{Statistical Analysis of Tap Tone Diagnosis}

The study formulates a visual diagnostic method for external wall tiles. However, visual inspection only applies to tiles that have already peeled off, and no further inspection can be made on tiles that have no obvious signs of peeling off. As such, the study also proposes adoption of the tap tone diagnostic method. The tap tone diagnostic method is the most convenient, economical and widely used evaluation method for inspecting surface defects. Tile inspection is normally combined with other inspection methods (such as the visual inspection method) 
as a basis for inspection of the condition of wall tile deterioration.

The theory behind the tap tone diagnostic method is determination through sound frequency. Besides pitch, sound also has intensity and tone. Generally speaking, pitch, intensity (loudness) and timbre are the three main elements of sound. The pitch of a sound is determined by its frequency of vibration. A higher frequency of vibration indicates a higher pitch, and a lower frequency of vibration indicates a lower pitch. The intensity of sound is determined by the vibration magnitude (amplitude) of the sound wave. Higher amplitude indicates a more powerful sound wave, and thus a louder sound. With this as a basis, with the different sounds generated from tapping on normal and deteriorated tiles with a tap tone diagnosis stick, the study uses Fast Fourier Transform to determine a spectrogram. Frequency $(\mathrm{Hz}, \mathrm{x}$-coordinate) and amplitude (V, $y$-coordinate) are used as a basis to determine the degree of tile deterioration. Spectrograms from the tap tone diagnosis are shown in Figure 2. It can be seen that the spectrogram's peak and trough for normal tiles show a stable frequency, while deteriorated tiles show apparent instability.

The study carried out tap tone diagnosis on 34 buildings whose CI values from visual inspection fall within Grade 2 and Grade 3 (four facades for each building); and there 177 areas of deterioration out of 680 tap tone diagnostic tests. The study deems the first peak of the spectrogram as noise, the beginning of the second wave as the start point of deterioration sound, and its end point as the end point of the deterioration sound. The spectrogram is then segmented by lattice points. Further statistical analysis of the 177 deteriorated areas shows that the average start point of deteriorated tiles is $239 \mathrm{~Hz}$, while that for the end point is $761 \mathrm{~Hz}$. The deterioration extent is indicated by the shaded portion.

The study suggests that upon tap tone diagnosis, if the Fast Fourier Transform graph shows a frequency from 200 to $800 \mathrm{~Hz}$, it can be speculated that there is a cavity in the tiles. If tap tone diagnosis is required, it is suggested to tap at least 5 spots on the facade to increase overall detection accuracy. The study tentatively recommends that if the tile deterioration ratio exceeds $50 \%$, immediate overall facade renovation of the building should be carried out. If the tile deterioration ratio is less than $50 \%$, then safety measures to prevent surrounding objects from
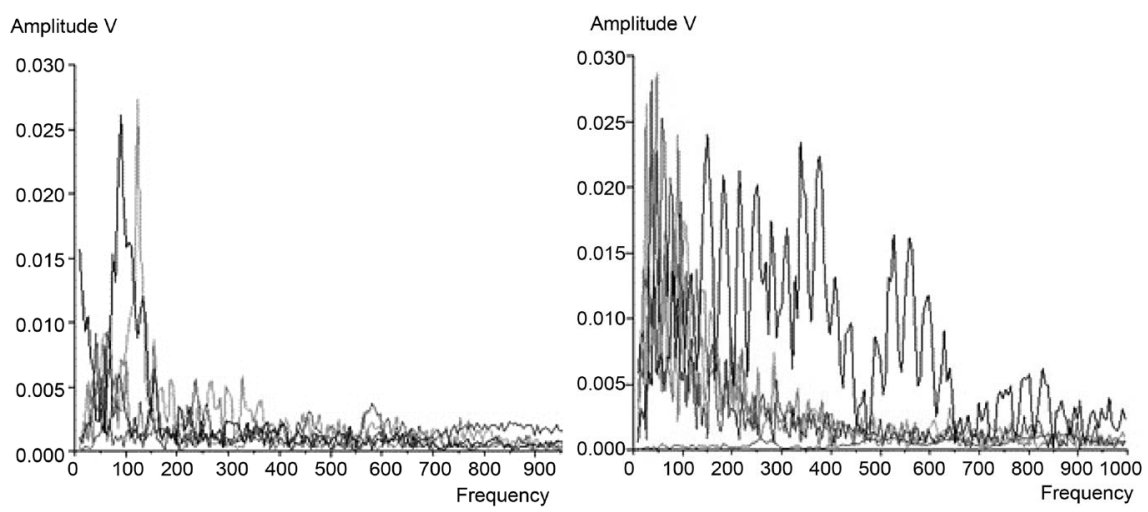

Figure 2. Transformed spectrum for tap tone diagnosis on deteriorated tile. 
falling should be immediately imposed.

\section{Case Study and Diagnosis}

This study investigated 46 building cases in the National Taiwan University. Figure 3 is the diagnosis results. Total of 34 buildings, CI values are categorized into the grade 2 and 3 . This study used lattice segmentation method for analyzing 177 tiles deterioration image spectrums. It is found that the deterioration of the tiles starts at frequency average about $240 \mathrm{~Hz}$ and ends at about $760 \mathrm{~Hz}$. Deterioration hatched range shown in Table 6 and Table 7.

The study consolidates results and recommendations of visual inspection and tap tone diagnosis, and proposes a diagnostic criteria and standard operating procedures for external wall tile deterioration diagnosis of Taiwan buildings, as shown in Table 8 and Figure 4. Infrared thermal images of deterioated wall tiles are also carried out for future research as shown in Figure 5.

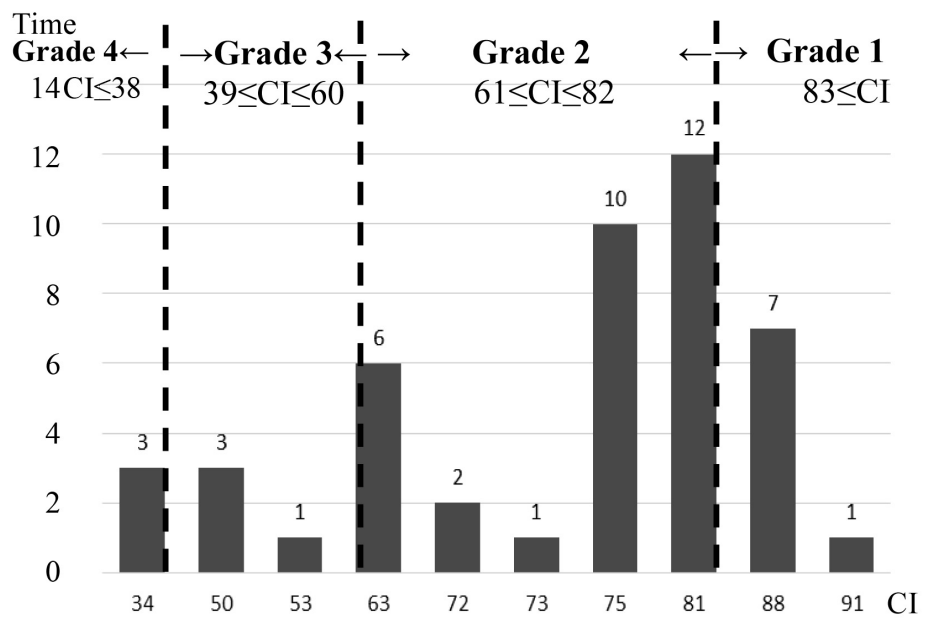

Figure 3. 46 cases diagnosis results of National Taiwan University.

Table 6. Case A of tap tone and visual diagnosis results.

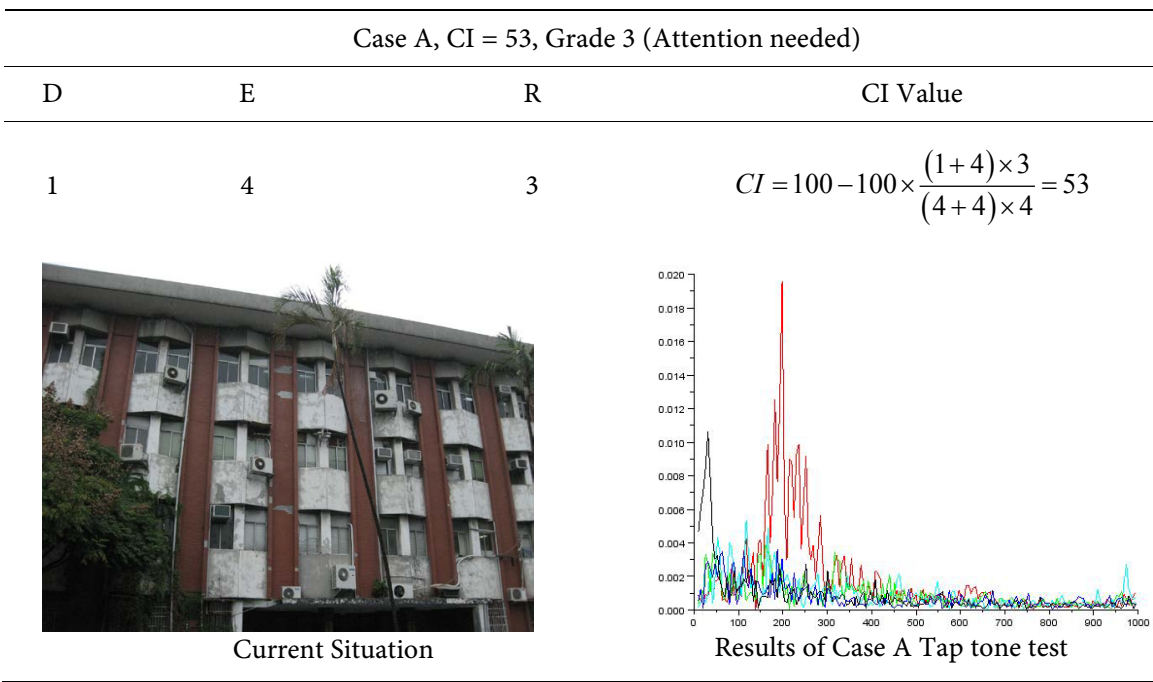


Table 7. Case B of tap tone and visual diagnosis results.

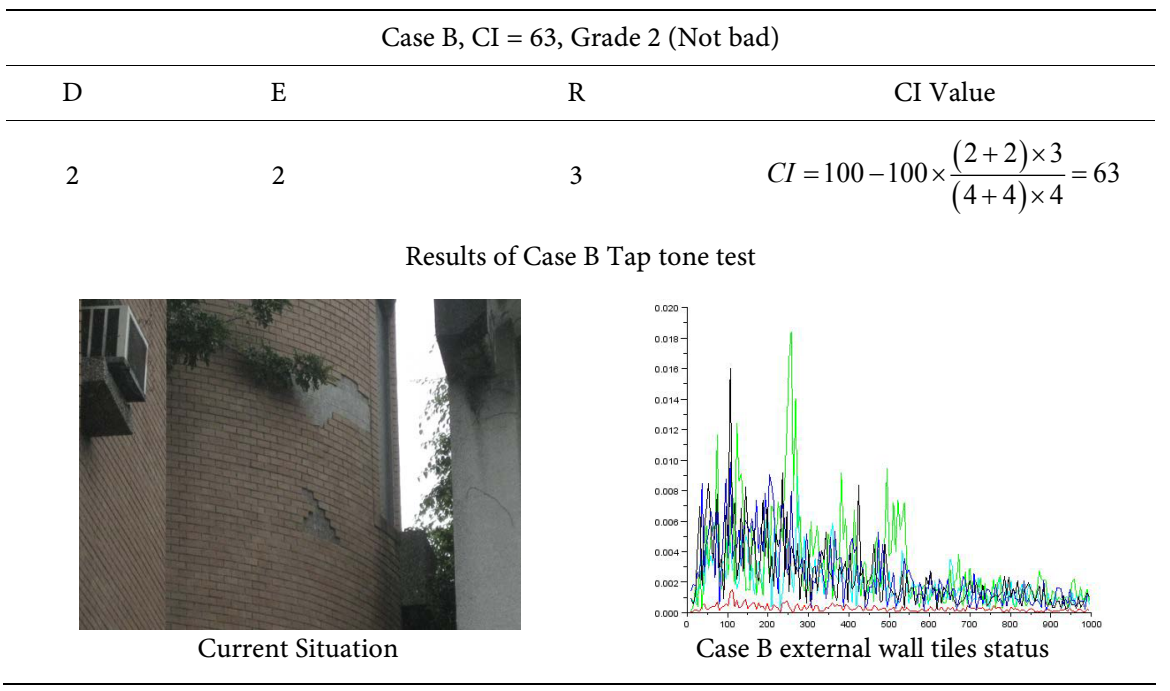

Table 8. Public safety classification of the external walls tiles of buildings.

\begin{tabular}{|c|c|c|c|c|}
\hline $\begin{array}{l}\text { Diagnostic } \\
\text { Level }\end{array}$ & Method & $\begin{array}{l}\text { Condition } \\
\text { Index } \\
\text { classification }\end{array}$ & $\begin{array}{l}\text { Determine } \\
\text { the grade }\end{array}$ & Proposed renovation principle \\
\hline \multirow{4}{*}{ Stage 1} & \multirow{4}{*}{$\begin{array}{c}\text { D.E.R } \\
\text { Visual } \\
\text { Diagnostic } \\
\text { Method }\end{array}$} & $83 \leq \mathrm{CI}$ & 1 (Good) & $\begin{array}{l}\text { Healthy, no immediate harm, } \\
\text { regular check once a year }\end{array}$ \\
\hline & & $61 \leq \mathrm{CI} \leq 82$ & 2 (Not bad) & $\begin{array}{c}\mathrm{R}=1 \text {, check once a year. } \\
\mathrm{R}=2,3 \text {, partial external wall } \\
\text { tap tone diagnosis } \\
\text { (top and ground floor) } \\
\mathrm{R}=4 \text {, comprehensive external } \\
\text { wall tap tone diagnosis }\end{array}$ \\
\hline & & $38 \leq \mathrm{CI} \leq 60$ & $\begin{array}{l}3 \text { (Attention } \\
\text { needed) }\end{array}$ & $\begin{array}{c}\mathrm{R}=2,3 \text {, partial external wall tap } \\
\text { tone diagnosis } \\
\text { (top and ground floor) } \\
\mathrm{R}=4 \text {, comprehensive external } \\
\text { wall tap tone diagnosis }\end{array}$ \\
\hline & & $\mathrm{CI}<38$ & $4(\mathrm{Bad})$ & $\begin{array}{l}\text { External wall renovation are } \\
\text { recommended }\end{array}$ \\
\hline \multirow[b]{2}{*}{ Stage 2} & \multirow{2}{*}{$\begin{array}{l}\text { Tap Tone } \\
\text { Method }\end{array}$} & \multicolumn{2}{|c|}{ no significant peak } & Check once a year \\
\hline & & \multicolumn{2}{|c|}{$\begin{array}{c}\text { frequency peaks in } \\
\text { between } 240-760 \mathrm{~Hz}\end{array}$} & $\begin{array}{l}\text { Based on user demand, overall } \\
\text { renovation }\end{array}$ \\
\hline
\end{tabular}

\section{Conclusions and Recommendations}

Since the construction boom in the 1970s in Taiwan, many building external wall have suffered natural deterioration, and many incidents of external wall tiles falling have occurred, with some even resulting in fatalities. As the number of such cases has increased, a complete external wall tile diagnostic system is required. This study proposes public safety visual diagnostic models for external wall tiles of buildings, including D.E.R. visual diagnostic concepts, diagnostic content and diagnostic evaluation standards. It also offers a public safety grading 


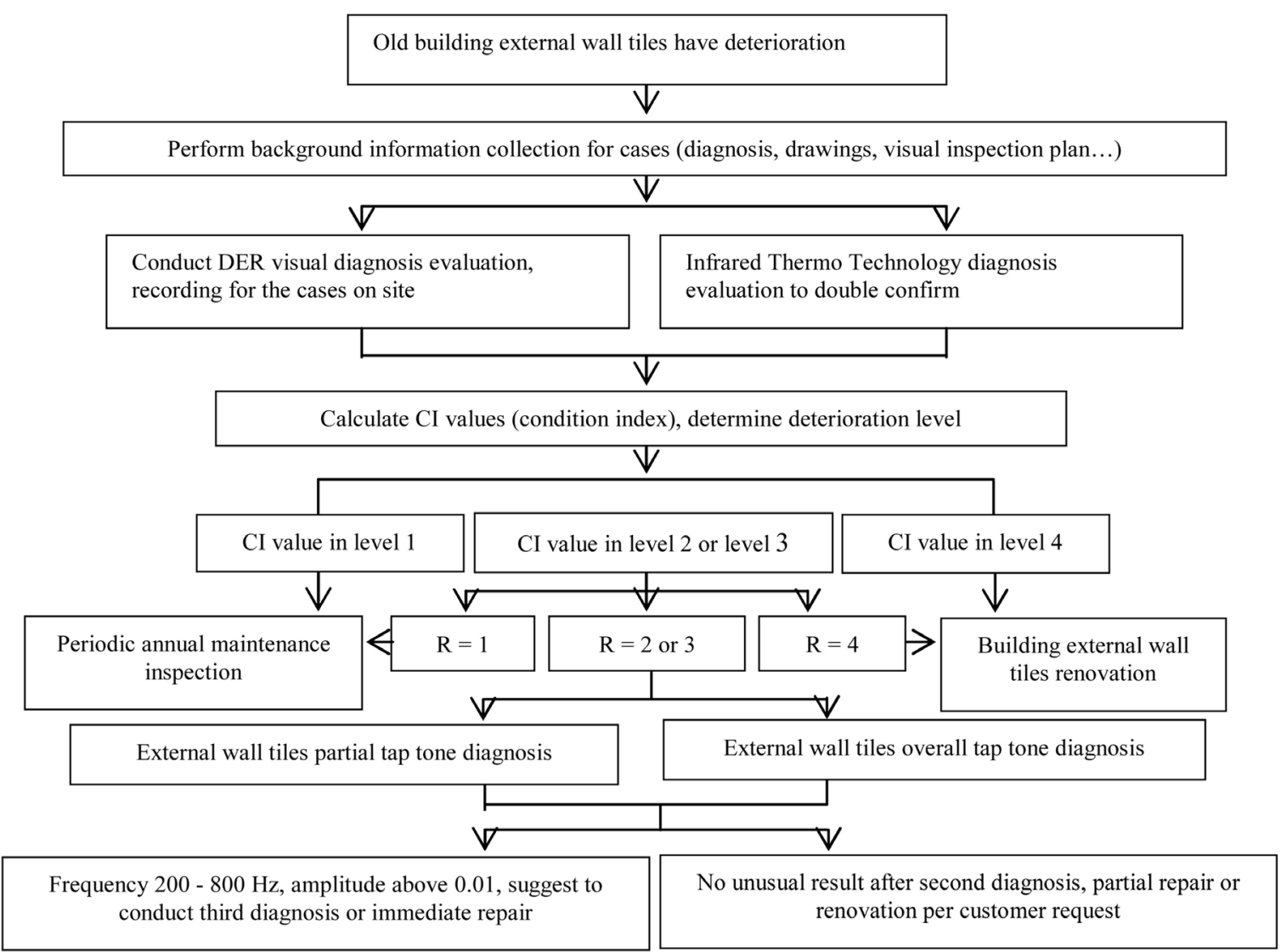

Figure 4. Tile deterioration diagnosis standard operation procedures.
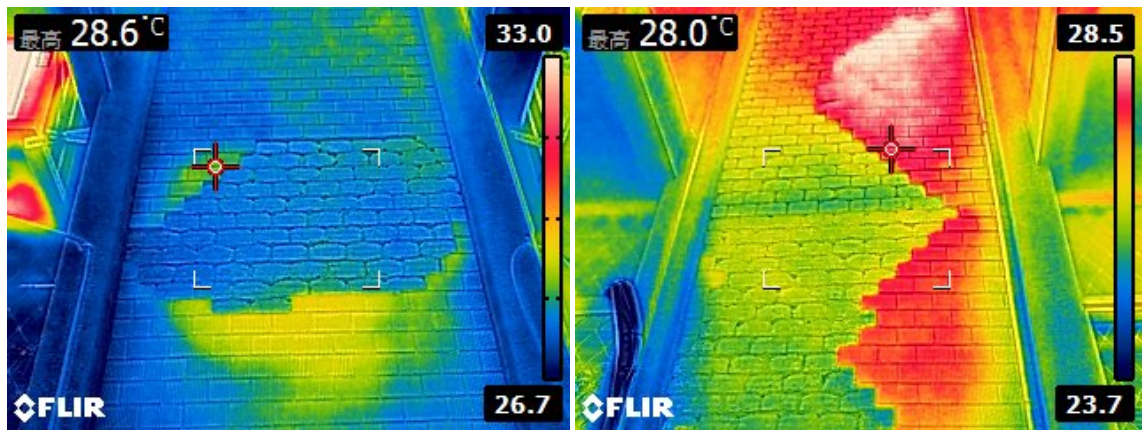

Figure 5. Infrared thermal images.

system for external wall tiles, as well as suggesting the adoption of tap tone diagnosis on tiles that potentially have significant impact on public safety. It also verifies the developed evaluation model, and proposes countermeasures and recommendations for deterioration conditions. The conclusion and recommendations of the study are as follows.

\subsection{Conclusion of the Study: Establishment of a Public Safety D.E.R. Visual Diagnosis Model for External Wall Tiles of Buildings}

The study establishes a D.E.R. visual evaluation model, "The visual diagnostic 
evaluation method for external wall tiles of buildings". This model includes deterioration degree, deterioration extent and public safety impact (Degree, Extent, Relevancy) of external wall tiles of buildings. Scores range from 0 to 4; 1 being optimal condition, 4 the worst condition. For a more accurate study of the condition of building external walls, the study established a D.E.R. visual inspection condition indicator (CI). Results can be categorized into four ranges based on mean and one standard deviation. Grade 1 is the best condition, while Grade 4 is the worst.

To reduce visual inspection errors, if the condition indicator is Grade 2 and $\mathrm{R}=$ 1 , it is recommended to inspect at least once per year. If $\mathrm{R}=2$ or 3 , it is recommended to perform partial facade (top floor and 1st floor) tap tone diagnosis. If $\mathrm{R}=4$, overall external wall tiles tap tone diagnosis should be carried out. If the condition indicator is Grade 3, and $\mathrm{R}=2$ or 3, it is recommended to carry out partial facade (top floor and 1st floor) tap tone diagnosis. If $\mathrm{R}=4$, overall facade tap tone diagnosis should be carried out.

Through visual diagnostic results, the study carried out tap tone diagnosis on 34 buildings. Based on the test results, the study recommends that for frequencies between 200 and $800 \mathrm{~Hz}$ on the spectrogram, it can be deduced that a cavity is present in the tiles, and this can be used as basis for determining tile deterioration.

\subsection{Recommendations}

The study recommends a review of existing laws and regulations, to determine whether new provisions need to be added, content of existing laws needs to be amended, or a new regulatory approach adopted. As there are no relevant control regulations in existing building laws in Taiwan, the study recommends referencing the mandatory building inspection regulations of Hong Kong, a territory with similar socioeconomic status to Taiwan. Hong Kong regulations stipulate mandatory inspection of public and private buildings that are more than seven stories high, whose adjacent roads are 20 meters or wider, and that are more than 20 years old, since these buildings are seen as having a greater impact on public safety. As it is difficult to impose mandatory inspection on private buildings, this study recommends implementation could begin with public buildings. Starting with public buildings, more detailed discussions can be held to include the impact on public safety of external wall tiles in Taiwan's building regulations.

\section{Acknowledgements}

This research was supported by the Ministry of Science and Technology (MOST 103-2221-E-002-235).

\section{References}

[1] Chang, C.Y. (2006) The Concept and Implements for Building Medicine. National Taiwan University Press, Taipei. 
[2] Tseng, C.H., Hsu, S.K., Wu, P.H., Yau, N.J., Chen, M.C., Yeh, C.C., Tsai, H.C. and Liao, H.K. (2011) A Study on Drafting the Bridge Visual Inspection and Evaluation Manual. Ministry of Transportation and Communication Press, Taipei.

[3] Chiang, L.W., Guo, S.J. and Chang, C.Y. (2014) The Model of Visual Inspection for Building External Wall Deterioration Tiles. Journal of Architecture, 87, 49-66.

[4] Guo, S.J., Huang, S.M., Chang, C.Y. and Chiang, L.W. (2011) The Research of Building Siding Health Check and Renovation Assessment System. Ministry of the Interior Press, New Taipei City. 